\title{
NUEVAS PERSPECTIVAS Y PARADIGMAS DE LAS POLÍTICAS PÚBLICAS SOCIALES EN TIEMPOS DE CRISIS
}

\author{
NEW PERSPECTIVES AND PARADIGMS OF PUBLIC SOCIAL POLICIES IN TIMES \\ OF CRISIS
}

José Manuel Canales Aliende

Universidad de Alicante. España/Spain jm.canales@ua.es

\section{RESUMEN}

El artículo analiza el impacto de la crisis múltiple actual del Estado de Bienestar en las políticas públicas sociales, en un contexto de sociedades plurales y complejas, haciendo hincapié en las diversas clases y características de las mismas, así como en una serie de propuestas y soluciones alternativas.

\section{PALABRAS CLAVE}

Crisis, Welfare State, políticas públicas sociales, gobernanza, administración pública, gestión pública.

\section{SUMARIO}

1. Introducción. 2. Las principales causas de la aparición de la crisis del Estado de Bienestar. 3. La crisis actual del Estado de Bienestar en el marco actual de la globalización. 4. La incidencia del Estado de Bienestar en el sector público. 5. Las principales características de las políticas públicas sociales. 6. Algunas consideraciones sobre las políticas públicas sociales en Iberoamérica. 7. Las principales clases de las políticas públicas sociales. 8. La necesidad de una Administración Pública profesional y especializada para la gestión de las políticas públicas sociales. 9. Principales conclusiones y propuestas. Bibliografía.

\section{ABSTRACT}

This article analyze the impact of the actual plural crisis of the Welfare State in the public social policies, in a contest de complex and plural societies, speaking about its different typologies and characters, and the same time suggest different proposals and alternative solutions.

\section{KEYWORDS}

Crisis, Welfare State, social public policies, governance, public administration, public management.

\section{CONTENTS}

1. Introduction. 2. The principals points of the origin in the crisis of the Welfare State. 3. Crisis of the Welfare State at the context of globalization. 4. The actual crisis of the Welfare State and his effect in the public sector. 5. The principal characters of the public social policies. 6. Some reflections about the public social policies in Latin America. 7. The different typologies of the public social policies. 8. The needed of one professional and specialized Public Administration for the management of the social public policies. 9. Principal conclusions and proposals. References. 


\section{BREVE INTRODUCCIÓN Y PLANTEAMIENTO GENERAL}

Estamos inmersos, como es sabido, en una situación profunda y estructural de crisis, que es compleja y polifacética. No es sólo una crisis económica, sino también social, política, cultural, institucional, ecológica, y de valores.

Se ha dicho que el presente siglo XXI será un siglo de valores y principios o no será, frente a las corrientes hasta hoy imperantes, del individualismo político, del darwinismo social, del economicismo ultraliberal, del consumismo desmedido, de la degradación medioambiental, de la falta de buen gobierno y de transparencia, de la corrupción política y administrativa, etc.

Todo lo anterior se va a producir además, en un contexto caracterizado sustancialmente por la globalización y la competitividad, por el riesgo global (Beck, 2005), por la deslocalización, por la precarización de empleos y de salarios, en una economía y de sociedad del conocimiento; y de crisis del sistema político clásico, y del modelo de Estado.

A su vez, la crisis del sistema político y del modelo de Estado, antes mencionado, va a tener múltiples causas, se va a manifestar en diversos aspectos, y va a tener características y efectos plurales.

El sistema político clásico representativo y surgido con el Estado Liberal de Derecho, y con el modelo de Estado-nación imperante fruto de él; no sólo ha desaparecido, sino que también y además se ha deslegitimado política y administrativamente. Basta decir sintética y sustancialmente, que el proceso de globalización ha inserto el modelo clásico del sistema político y estatal, en un nuevo entorno en el que no es el actor principal, y que están sujetos ambos a las actuaciones y presiones de Agencias, instituciones y élites mundiales (Rothkopf, 2008), no sólo a veces incontrolables y no democráticas, sino también y sobre todo opacas.

Por otro lado, además los procesos de respuesta a la crisis del Estado-nación, de integración supranacional (como la Unión Europea, MERCOSUR, etc.) o los procesos de descentralización subnacionales o regionales en el seno de los propios Estados, han producido un "vaciamiento" o pérdida de competencias por arriba y por debajo de los mismos.

En cuanto a la crisis de insuficiencia del modelo clásico del sistema representativo y de partidos; éste se ha visto desbordado por los planteamientos y las demandas de la sociedad civil y de la ciudadanía, que instan a una democracia más completa, fuerte, deliberativa , reflexiva y participativa; y ello a través de una serie de nuevos mecanismos y vías de participación más directas, y mediante el protagonismo de los diversos actores sociales (tales como las ONG.'s; los movimientos sociales y asociaciones culturales de diversos caracteres; los movimientos ecologistas, feministas e indígenas; las cooperativas, etc.).

Como se ha dicho, la crisis del Estado hoy es diversa (política, social, territorial, ideológica y de valores, y de funciones básicamente), y entre ellas destacaría la crisis y en algunos casos, la quiebra del Estado de Bienestar o Welfare State, el cual es una forma política histórica concreta, relativamente creciente, que se ha manifestado de diversas formas y con diferentes características en diversos países del mundo.

La aparición y la consolidación y el desarrollo del Estado de Bienestar, no van a ser de una forma espontánea y rápida, sino que a ser fruto de un largo y complejo proceso, y a la vez fruto de numerosas reivindicaciones sociales (básicamente de los movimientos y sindicatos obreros, de los partidos de clases, de las aportaciones del socialismo científico y del utópico, y de la Doctrina Social Católica). Por el contrario, la crisis por causas diversas, y el desmantelamiento del Estado de Bienestar, es hoy un proceso rápido y a veces 
improvisado. Además, resulta llamativo el hecho de que la desaparición del Estado de Bienestar en algunos países, se está operando, cuando éste aún no se había desarrollado suficientemente.

El contexto actual de la globalización va a implicar también unos cambios estructurales de la sociedad y del modelo de relaciones laborales. Los fenómenos de la diferenciación, la interdependencia, la fragmentación, la complejidad social; y la decadencia y la desaparición progresiva de las clases medias (Fukuyama, 2012), aparecen hoy como relevantes.

La crisis actual entre otros efectos, está produciendo además un temor e inseguridad acendrados en la población, y un debilitamiento progresivo de la democracia y de sus instituciones y del contrato social, en la ciudadanía y en la sociedad civil (Estefanía, 2012).

Ahora bien, esta crisis múltiple actual, también y sobre todo es una crisis de virtudes y valores públicos. En la contemplación del fenómeno actual de la crisis, hay que tener en cuenta y examinar también, cual es el discurso y el contenido del lenguaje de la clase política y de los distintos medios de comunicación social y de las redes sociales. En este sentido, resulta sorprendente cómo por parte de algunos de los actores sociales y en algunos países, se culpa de la pobreza encima, a las clases más desfavorecidas. Resulta no sólo sorprendente, sino además más bien alucinante, que a las clases más desfavorecidas junto a la disminución y/o eliminación de sus prestaciones y derechos públicos, se les responsabilice también de los fracasos financieros del capitalismo y de sus gestores bancarios y empresariales.

Las políticas públicas sociales son el principal instrumento, y a la vez la expresión de derechos sociales y de la realidad del Estado de Bienestar; las cuales si bien con tendencias y características comunes, aparecen con propia idiosincrasia en cada país.

En ocasiones hoy, fruto del neoliberalismo imperante, se consideran a las políticas públicas sociales como residuales y derivadas de las políticas públicas económicas; cuando ambas son relevantes y complementarias a la vez; y éstas no son un gasto sino una inversión, como se ha demostrado suficientemente, e implican un "valor añadido" digno de atención, y un factor determinante de la cohesión económica y social.

"La democracia supone, por tanto, una sociedad civil fuertemente estructurada, asociada a una política integrada..." (Touraine, 1993:421), en la que finalmente el Estado sea un medio y no un fin, al servicio de la ciudadanía.

\section{LAS PRINCIPALES CAUSAS DE LA APARICIÓN DE LA CRISIS DEL ESTADO DEL BIENESTAR}

No existe una sola y única variable explicativa del surgimiento de la crisis del Estado del Bienestar, a partir de los años setenta. El cuestionamiento y la crítica al mismo, es un fenómeno plural y complejo a la vez, fruto de un proceso histórico determinado, pudiéndose señalar causas de distinto tipo.

Las razones principales o causas políticas de su cuestionamiento o crisis, fueron las siguientes: 1) el exceso de carga del Estado, y la limitación de las posibilidades e iniciativas de la sociedad y los individuos; 2) la crisis de gobernabilidad, y la demanda excesiva de prestaciones de los ciudadanos; 3) la tecnificación de la política; 4) el déficit democrático; 5) la eliminación de la discusión pública y la comunicación de la opinión pública; 6) la mediación y el monopolio de los medios de comunicación social; 7) el neocorporativismo; 8) la corrupción política y administrativa; 9) la deslegitimación del sistema político. 
A su vez, entre las principales razones o causas económicas de la crisis del Estado de Bienestar, podrían señalarse las siguientes: 1) el déficit público; 2) el exceso de gasto público; 3) la presión fiscal abusiva y progresiva; 4) el proteccionismo estatal; 5) la falta de innovación tecnológica; 6) la ausencia de calidad y mejora de los servicios públicos; 7) la falta de competitividad; 8) la limitación de la iniciativa privada y el condicionamiento del libre mercado; 9) el absentismo laboral; 10) la ineficacia e ineficiencia del sector público; 11) la improductividad en ocasiones, del sector público.

Por otro lado, la crisis del Estado de Bienestar, unida a la crisis fiscal del Estado, se va a producir pues en un entorno de sociedad compleja postindustrial y postmoderna; con unas nuevas realidades y unos problemas de distinto tipo; y con una gran incertidumbre sobre el futuro de las sociedades civiles y de sus modelos tradicionales de Estado-nación.

Los nuevos valores y tendencias que intentarán sustituir a los del Estado de Bienestar, serían básicamente los siguientes:

a) Frente a una valoración preponderante de las fuerzas y actores sociales y políticas, y de lo colectivo; una exaltación del individualismo. Es decir, el individualismo antes y por encima de la sociedad civil.

b) Frente a lo público; el mercado y lo privado.

c) Frente a la política de gestión de la demanda para dirigir la economía; la política de la oferta.

d) Frente al objetivo de pleno empleo y de estabilidad laboral; la estabilidad de los precios.

e) Frente a la política fiscal; las políticas monetaristas.

f) Frente a la cohesión y la solidaridad social; el "darwinismo social".

g) Frente a la planificación participativa y estratégica; una fe ciega en el mercado, en su autorregulación, y en su funcionamiento transparente y leal.

h) Frente a las nacionalizaciones, y a un sector público estratégico y motor de la economía; las privatizaciones como alternativa única posible.

i) Frente a la garantía y la seguridad de los derechos laborales; la desregulación del mercado laboral.

j) Frente al Estado de Bienestar y sus prestaciones; el acoso y derribo del mismo.

k) Frente a la redistribución de la renta con un carácter social y equitativo por parte del Estado; la redistribución fruto del mercado y del capital.

1) Frente al gasto público, preferentemente en materia social; la reducción del gasto público por considerarse ineficaz e improductivo.

m) Frente a la imposición tributaria de carácter progresivo y redistributivo; una imposición tributaria indirecta y de contenido mínimo.

n) Frente a una solidaridad interpersonal e interterritorial; el beneficio individual como objetivo único.

\section{LA CRISIS DEL ESTADO DE BIENESTAR EN EL MARCO ACTUAL DE LA GLOBALIZACIÓN}

El escenario o contexto en el que se produce la actual crisis del Estado de Bienestar hay que decir ante todo que es novedoso, ya que se produce en el marco de la llamada mundialización o globalización, la cual tiene una dimensión múltiple y no solo económica; aconteciendo tras la caída del muro de Berlín, y la desaparición de los modelos y experiencias del llamado "socialismo real". 
La globalización es la principal característica del postcapitalismo, y es un proceso en virtud del cual las economías nacionales se integran y dependen cada vez más de la economía y de los mercados internacionales, disminuyendo de este modo la capacidad de decisión y de influencia de los gobiernos nacionales.

Globalización, mundialización y simultaneidad, son los principales aspectos de un proceso que caracteriza a la sociedad actual, y que como consecuencia de los mismos, se originan unos nuevos desafíos y unos nuevos problemas.

En el proceso de globalización, hay dos sectores que son sus principales pilares básicos, aunque no los únicos, a saber: los mercados financieros, y los medios de comunicación.

Ahora bien, la globalización de la economía, no implica la desaparición de las tensiones por el dominio del mercado, ni por el reparto de los espacios de influencia en el mismo. Por otra parte, la globalización no es una panacea ni una solución mágica, sino que por el contrario va a producir nuevos problemas, entre los que se podrían citar los siguientes: a) el paro estructural; b) el empleo cada vez menos estable, indefinido y peor remunerado; c) la especulación e inestabilidad financiera y monetaria nacional; d) el empobrecimiento y la desintegración social progresiva de los países menos desarrollados; e) la degradación medioambiental; f) el mantenimiento de los gastos militares, a pesar de la guerra fría y de la política de bloques; g) la insuficiencia en la redistribución económica, y por causa de ello, la aparición de nuevos focos de pobreza; h) los desequilibrios territoriales; i) las nuevas demandas ciudadanas; j) los nuevos problemas urbanos, y en particular de concentración urbana y de marginación social en las grandes áreas metropolitanas; etc.

La economía mundial va a estar dominada por redes de producción, de gestión y de comunicación, conectadas a través de fronteras nacionales, superando éstas, y escapando así de la economía productiva y de la política económica de ámbito nacional; estando a su vez tales redes, en una constante movilidad y dinamismo, en la búsqueda de una huida acelerada de las regulaciones y controles de diverso tipo de los diversos países y de sus instituciones. Fruto de lo anterior, la característica esencial del capitalismo como monetario y productivo se va a transformar en un capitalismo especulativo y sin ningún control democrático. Los mercados nacionales van a depender de políticas supranacionales, muchas veces difíciles de prever.

El segundo sector relevante de la globalización, además del precitado de los mercados financieros, es el de los medios de comunicación, produciéndose en la actualidad una revolución del conocimiento a la que se une una rápida y masiva difusión de la información. Las "autopistas de la información" son hoy en día, lo que las infraestructuras del transporte supusieron en el siglo XIX. Además, las redes sociales suponen un nuevo actor en este contexto.

El mundo actual se caracteriza por una presencia masiva de los multimedia, existiendo tendencias conducentes a su desregulación publica, privatización, concentración, etc. La concentración de los medios de comunicación que a veces acontece, así como su manipulación, y la simplicidad del contenido de sus mensajes, etc., va a suponer a su vez, unos nuevos problemas de carácter social y político, y sobre todo un auténtico reto al sistema político.

La globalización como se ha dicho anteriormente, no tiene sólo un aspecto o dimensión económica, sino también política. La visión de la sociedad es hoy de ámbito mundial o global.

Como consecuencia del fenómeno antes señalado, se producen a su vez, entre otros, los siguientes hechos y problemas: a) hay globalización de mercados y de capitales, pero no de 
personas y del trabajo; b) se produce una crisis del Estado-nación y de los modos de gobernar en él; c) existe una modificación estructural de los mercados de trabajo y de las políticas públicas de empleo; d) acontece una desconexión entre las élites políticas y los ciudadanos; e) aparece una crisis de la representación política tradicional, junto con una apatía e individualismo progresivo de los ciudadanos, y a veces una desafección de los mismos del sistema; f) surgen nuevos focos de terrorismo, de violencia y de marginalidad social; g) se transforman y aparecen nuevos movimientos migratorios; h) irrumpen los grupos de presión empresarial en la vida política con una gran intensidad; i) se debilitan y empobrezcan las clases medias; etc.

En el ámbito cultural, sin perjuicio de una mayor difusión de la cultura y de los conocimientos, se producen a su vez, entre otros, los hechos y fenómenos siguientes: a) un peligro de pensamiento único, frente a la pluralidad; b) el individualismo exacerbado aparece como el gran descubrimiento el neoliberalismo imperante; c) la eficiencia, y no la eficacia y la equidad, aparece como la única finalidad y legitimidad públicas; d) el interés general como valor político y jurídico, se arrincona; e) la pérdida o debilidad de las utopías; f) la desaparición y la minusvaloración de las ideologías y de los valores públicos; g) la ausencia de un modelo de sociedad integrada multicultural.

El modelo clásico del Estado de Bienestar, presuponía una estabilidad económica y un modelo de crecimiento económico basado en el empleo estable, que las turbulencias y la dinamicidad de la globalización han trastocado esencialmente.

\section{LA INCIDENCIA DEL ESTADO DE BIENESTAR EN EL SECTOR PÚBLICO}

Es cierto que como consecuencia de la consolidación y el desarrollo del Estado de Bienestar, la presencia del Estado en la sociedad civil aumentó cuantitativa y cualitativamente, incrementándose también el gasto público, el número de empleados públicos, y el volumen del aparato administrativo.

Además, el fenómeno del desarrollo y consolidación del Estado de Bienestar, es coincidente con una fragmentación y una diversidad de Administraciones Públicas y de procesos de descentralización político-administrativa, que implicaron la ruptura del viejo modelo del Estado Liberal y de su Administración Pública jerarquizada y centralizada.

Lo anterior, condujo a la postulación de un Estado intervencionista, o "manager", según la terminología de García Pelayo, y prestador directo de múltiples servicios y bienes públicos, y en particular de carácter social.

Como alternativa a esta situación precedente descrita de forma sucinta, a partir de la década de los sesenta, como antes se ha dicho, aparecieron las primeras opiniones y tendencias, de distinto contenido y características, impregnadas de un neoliberalismo privatizador a la ultranza, siendo sus máximos exponentes en la década de los setenta el modelo tatcheriano en el Reino Unido y el reganismo en los Estados Unidos. Se fomentó un capitalismo patrimonializador del Estado, fundado en la concesión y subvenciones públicas.

La privatización, la desregularización, la contratación externa de los servicios públicos, la incorporación al sector público de técnicas y gerentes del sector privado, fueron entre otros, los fenómenos iniciados en la década de los setenta, y luego generalizados con carácter casi universal, con la excusa de la modernización administrativa.

El economicismo y el gerencialismo exagerados, la reducción el sector publico de forma genérica sin evaluar previamente materias y sectores concretos, y la búsqueda de la 
rentabilidad máxima a través de la técnica del coste-beneficio; aparecieron como los objetivos prioritarios y únicos, de muchos de los procesos de modernización administrativa, olvidando los importantes aspectos básicos también de este proceso, como son los aspectos políticos, los culturales y los psicosociales. La modernización administrativa entendida de esta forma sesgada y unidimensional, olvidó que la modernización política es previa, condicionante, y complementaria de ella, además de la importancia que tiene la "cultura administrativa" en los procesos de cambio.

$\mathrm{Si}$ bien como consecuencia de los procesos experimentados de modernización administrativa, en muchas ocasiones el déficit público disminuyó notablemente o se eliminó mediante la disminución del sector público, la aminoración de los costes, o por la reducción progresiva del gasto público; no obstante también, se produjo una cierta sensación de desmoralización, desmotivación, y de pérdida de valores en el sector público, y en particular en sus empleados.

Además de lo anterior, la exaltación de la eficiencia y de la economicidad como metas y valores únicos máximos e indiscutibles; provocaron como efecto también, una minusvaloración, y a veces una inaplicación (con efectos graves) de otros principios y valores incardinados en la historia del Estado de Derecho contemporáneo, y en particular de la seguridad jurídica y de la igualdad ciudadana.

Algunas manifestaciones del ataque y de la crisis del Estado de Derecho, conquista histórica irrenunciable por otro lado, fueron el olvido y la inaplicación de los sistemas y técnicas jurídicas tradicionales de control jurídico y económico financiero, con la excusa de su lentitud y formalismo; potenciándose una huída hacia su aplicación al sector publico del derecho privado, como si este no estuviese ciertamente vinculado a la idea y al principio de la legalidad y del Estado de Derecho.

El modelo de las Agencias "Ejecutivas" e "Independientes" fue consagrado dogmáticamente y a priori, como la estructura organizativa perfecta y más ágil e idónea para la nueva situación; sin reparar en su posible no validez universal para todos los sectores, ámbitos y contextos del sector público de cada país. La creación de tales Agencias no siempre supuso por otro lado, una mayor transparencia, ni una mayor responsabilidad en la gestión.

La politización y la desprofesionalización de la función pública, fueron otros de los fenómenos producidos (quizás no querido en todas las ocasiones) como consecuencia de las nuevas experiencias y tendencias modernizadoras, rompiéndose así los principios clásicos derivados del Estado de Derecho contemporáneo, de la profesionalidad y de la neutralidad, conquista por cierto relevante frente al precedente del spoil system. Los gabinetes políticos, los órganos staff, las fundaciones y las entidades privadas, etc., aparecieron en muchas ocasiones; con un papel y una misión de alternativa y sustitución de la función pública profesional, y no como unos instrumentos validos y complementarios de ésta, y con sus propias tareas, en un sistema político pluralista y democrático.

Por otro lado, el exceso de la presión fiscal y del déficit público, simultáneos a un aumento progresivo cualitativo y cuantitativo de las demandas ciudadanas, provocaron también en numerosos supuestos una venta, a veces injustificada y precipitada, de empresas públicas; las cuales fueron compradas muchas veces por grupos de empresas oligopolísticas o empresas multinacionales.

La relajación o la inaplicación de las técnicas garantistas del Derecho Público provocaron en muchas ocasiones, y en particular en los países latinos de tradición administrativa francesa, una praxis y/o un fomento de la corrupción política y administrativa; siendo 
especialmente relevante lo antes dicho, en los ámbitos de la contratación y de la concesión de obras y servicios públicos. El Estado de Derecho, de valores y principios públicos y de igualdad surgido con el Estado Liberal, e inspirado en la Revolución Francesa, se convirtió a veces en un Estado de "Derecho Privado".

A nivel político, en este período de crisis del Estado de Bienestar, acontece simultáneamente una potenciación del papel de los partidos políticos en los sistemas políticos, lo que se ha venido a llamar en la doctrina "Estado de Partidos", con un efecto en ocasiones disfuncional, ya que la oligarquía y la endogamia van a caracterizar a sus élites, en un detrimento de la transparencia y democracia debidas en los partidos políticos. Esta oligarquía partidocracia, debilitará a su vez también el papel del control de los parlamentos, así como de la opinión pública, creando una crisis en el sistema tradicional de representación y de la participación política.

Hay pues, una crisis simultánea y múltiple, una debilidad, una desorientación, y un cuestionamiento, no sólo del sector público, sino también y sobre todo del Estado, y de sus instituciones en el seno del sistema político.

La crisis de este modelo, pondrá en cuestión además las características tradicionales de las Administraciones Públicas, en un nuevo entorno caracterizado por la inestabilidad, la fragmentación y el cambio, siendo él mismo parte del problema. Por otro lado los criterios tradicionales imperantes (universalidad, igualdad e imparcialidad) en la prestación de los servicios públicos quedan bastante obsoletos; y hay que buscar criterios alternativos justos y actuales.

En cuanto a la gestión pública se va a ver afectada por una ruptura de sus límites tradicionales, haciéndola cada vez más transversal.

\section{LAS PRINCIPALES CARACTERÍSTICAS DE LAS POLÍTICAS PÚBLICAS SOCIALES}

Con un carácter previo a la definición, concreción y caracterización de las distintas públicas sociales en cada contexto; es preciso que esté claro el modelo adoptado de Estado Social, de discurso social, y de modelo social.

1) Hay que señalar en principio y en primer lugar que las políticas públicas sociales, son complementarias, y están en función de las políticas públicas económicas y financieras de cada país. Unas políticas económicas redistribuidoras de la renta, y unas políticas fiscales progresivas, tienen sin duda un gran impacto social. Ambas son pues interdependientes.

2) En segundo término, la finalidad y la orientación de las políticas públicas y sociales, no son sólo la de reparación y compensación de daños, y la satisfacción de necesidades sociales; sino también y además la de prevención y la de educación. Las políticas públicas sociales deberían ser pues, estratégicas, proactivas y prospectivas; y no sólo coyunturales y reactivas; y con un alto nivel de coordinación.

3) El proceso decisorio de las políticas públicas sociales es complejo, y mucho más si éste es participativo y negociador en el "neocorporativismo", surgido tras la segunda guerra mundial en los países occidentales, y se le añaden hoy los deseos añadidos de participación ciudadana a través de las diversas vías que se están creando para ello, y como expresión de la sociedad civil dentro del paradigma actual de la gobernanza.

4) Estas, además, son dinámicas y mutables (Sempere Navarro y otros, 2001:21) y, a la vez, heterogéneas, en función del contexto temporal y espacial. 
5) Su ejecución plantea problemas de evaluación, pero ésta no es imposible.

6) La tendencia progresiva hacia la focalización, la sectorización, y la personalización. La igualdad como finalidad de las políticas sociales, no se contradice con la priorización y/o especialización de sectores o grupos sociales a atender (especialmente los colectivos o grupos más débiles frente a la exclusión social). La equidad social es hoy prioritaria ante todo.

7) La importancia de la coordinación entre las instituciones públicas, y éstas con las privadas, cara a su ejecución.

\section{Algunas CONSIDERACIONES SOBRE LAS POLÍTICAS PÚBliCAS SOCIALES EN IBEROAMÉRICA}

El continente iberoamericano, con sus múltiples facetas y diversidades, experimenta en la actualidad lo que ha llamado "pobreza paradojal" (Klisberg, 2006:9); o lo que es lo mismo una moneda de dos caras, o una situación esquizofrénica; debido a la presencia simultánea de amplios niveles de pobreza, frente de la desigualdad, a la vez que un aumento económico en varios sectores y países.

La necesidad de un desarrollo integral basado en la ética, y en una filosofía y programa postconsenso de Washington, parece ser el camino más adecuado; y ello a través del fortalecimiento de la democracia y de sus instituciones, y por ende de sus políticas públicas. Estas a su vez, presentan una gran fragilidad institucional.

El pensamiento económico neoliberal, individualista y deshumanizado, necesita transformarse sobre todo en este continente en un nuevo capitalismo de rostro humano. El Capital Humano y el Capital Social enriquecen y completan las clásicas del capital físico o de infraestructuras y la de capital financiero. Las políticas ortodoxas, economicistas, y cortoplacistas, han fracaso y conducido a esta situación social.

Si bien es verdad que a nivel de opinión publica, la democracia como filosofía y como sistema de organización política está consolidada al menos formalmente; la democracia en su configuración institucional, en su orientación, y praxis es aun muy débil.

Los principales retos sociales, objeto de las políticas públicas sociales, serían básicamente los siguientes: 1) la lucha contra la desigualdad y la exclusión social; 2) la redistribución más justa de la renta, y de las riquezas; 3) la igualdad de acceso al crédito, a la educación y a la salud; 4) la priorización y la relevancia de éstas, y no degradarlas a un segundo plano respecto a las económicas; asignándoles los recursos necesarios.

Por otro lado además, éstas deberán ser también proactivas, y descentralizadas al máximo; y bien gerenciadas por profesionales conforme a un modelo de "servicio civil de carrera".

El desarrollo del voluntariado, de la responsabilidad social empresarial, y "el empoderamiento de los pobres", constituyen también hoy día unas fórmulas alternativas y complementarias del sector público (Klisberg, 2006:209).

En "América Latina, antaño terreno de experimentación privilegiado de las reformas de inspiración neoliberal, se ha convertido hoy en un laboratorio de experiencias sociales inéditos..." según Delcourt (2010:21), lo cual sin duda, y a pesar de la problemática existente, es esperanzador. 


\section{LAS PRINCIPALES CLASES DE LAS POLÍTICAS PÚBLICAS SOCIALES}

1) Respecto a las diferentes clases o tipologías de las políticas públicas sociales, se podrían citar las siguientes, en cuanto a su contenido:

a) Las políticas de salud, no sólo de mera prestación reparadora de las enfermedades físicas, sino también de las mentales; y también con un carácter preventivo y educativo.

b) Las políticas de Seguridad Social, con todas sus prestaciones, y con una financiación preferentemente "de reparto" frente al sistema de "capitalización, por ser el primero de ambos más justo. Se olvida a veces que el sistema público de la Seguridad Social, como ha puesto de relieve de forma unánime y constante la doctrina y la OIT., cumple además de la función reparadora de las necesidades sociales; otras dos también muy relevantes, y no susceptibles sólo de su contemplación en base a una visión y parámetros económicos, como son: a) la solidaridad interpersonal, intergeneracional e interterritorial; y b) la de cohesión y paz social.

La previsión social y los primeros seguros sociales, surgieron para lograr "la paz económica y social" frente a las injusticias sociales de su época; y luego la Seguridad social, básicamente a través de su potenciación y su universalización fruto del Informe Beveridge, fue un instrumento notable de desarrollo y de "homeostasis social".

c) Las políticas de Servicios Sociales, de contenido diverso, que se integran a su vez éstas o no según países, en el sistema público de la Seguridad Social. Su finalidad es la plena inclusión social. Las prestaciones por las diversas causas de la dependencia, es también una importante y novedosa política pública de servicios sociales, que a veces se incluye como en el caso alemán en el sistema público de la Seguridad Social.

d) Las políticas de Cohesión, Económica y Social, básicamente de planificación, adecuación y desarrollo territorial justo, en lo económico y social; básicamente a través de fondos diversos.

e) Las políticas Educativas y Culturales, en el más amplio sentido de sus fases y de contenido. La educación y la formación profesional, complementada por la cultural, es un subsistema y debe abordarse de forma integral y conjunta; dando prioridad a la etapa escolar.

f) Las políticas de Empleo, activas y no activas, en correlación con las educativas y formativas.

g) Las políticas de ayuda a familia o familiares, claves en cuanto no sólo las prestaciones y ayudas económicas, sino por el papel que juega la familia en la sociedad contemporánea.

2) A su vez, según el ámbito territorial de su incidencia y aplicación, puede hablarse de: a) políticas públicas sociales internacionales; b) la supranacionales; c) nacionales; d) subnacionales o regionales; y e) locales.

3) Según su ámbito de aplicación, puede hablarse de generales, y sectoriales o específicas.

4) En cuanto a su finalidad, cabía señalar las siguientes: a) reguladoras; b) redistributivas; c) preventivas; d) reparadoras; y e) de control y de sanción.

Las políticas de género, que se caracterizan por su gran transversalidad, no son consideradas por la doctrina como políticas sociales propiamente, pero sin duda tienen un gran impacto social. 


\section{LA NECESIDAD DE UNA ADMINISTRACION PÚBLICA PROFESIONAL Y ESPECIALIZADA PARA LA GESTION DE LAS POLÍTICAS SOCIALES}

Si siempre ha sido necesaria una Administración Pública Profesional, y no clientelar, para el logro de su eficacia; en el momento actual esa necesidad, se ve fortalecida por la complejidad y la diversidad social y económica del contexto en que ésta debe actuar.

El desarrollo y la aplicación adecuada de las políticas públicas sociales, sugieren a su vez una especialización en la Administración Pública, que las lleve a cabo; y además unos valores y ejemplaridad y principios públicos, y en particular de la ética pública. Diseñar y llevar a cabo las políticas públicas sociales, sin sensibilidad y valores sociales es impensable.

En ese sentido, Sen y Klisberg (2007:125), han señalado lo siguiente, sobre el papel de la función pública,: “... hay un cambio en marcha, en especial a nivel subnacional, conforme al cual las nuevas alianzas entre la élite profesional, los funcionarios públicos, la clase media y los pobres están impulsando actualmente la creación de instituciones más inclusivas y eficientes".

Las Escuelas de Gobierno, están siendo en muchos países de América Latina, una respuesta institucional para la capacitación simultánea (materias comunes) y a la vez especializada de líderes políticos y de líderes administrativos o directivos públicos. La capacitación y la motivación para "los asuntos públicos" y para la planificación y la gestión del cambio, es un auténtico reto, ya que hacen falta élites concienciadas y preparadas para ello, y no incapaces.

\section{PRINCIPALES CONCLUSIONES Y PROPUESTAS}

Ante todo hay que señalar que no existe una solución, ni un modelo mágico, ni universal, aplicable a la solución compleja de crisis que vivimos en el contexto difícil de la globalización. Cada sociedad y país, tiene sus propias características y problemática; pero no obstante, sí que cabrían hacer algunas consideraciones y propuestas personales de carácter general; las cuales son desgraciadamente por el momento en muchos casos, más un deseo que una realidad, a saber:

a) Ante la ausencia de una deseable y necesaria autoridad y gobierno mundial, o cosmopolita (Held, 2005), proceso largo y difícil sin duda; haría falta que las organizaciones supra e internacionales (ONU., OIT., Banco Mundial, FMI., etc.), llevasen a cabo unas nuevas tareas de regulación, coordinación, y de control de las empresas multinacionales, Agencias e Instituciones de calificación financieras existentes. La gobernanza es y debe ser hoy mundial, frente a una realidad y problemática global y a una sociedad civil global.

b) La potenciación, y la primacía de los principios y valores públicos, de contenido y carácter solidario, comunitario y equidad social, entre otros. La ejemplaridad pública (Gomá, 2009) y la ética pública (Cortina, 2012), implicarían entre otras medidas, las siguientes: “a) no empezar por recortar por lo más fácil, por los más débiles, sino por exigir la devolución de lo que se ha robado y reducir los sueldos de los implicados en la mala gestión; b) proteger a los más vulnerables, a los enfermos, los inmigrantes, los dependientes, los países en desarrollo, los niños. Y no sólo porque es la forma de lograr cohesión social, sino porque es su derecho de justicia, amén de una elemental obligación de solidaridad; c) acometer medidas de crecimiento, generadoras de empleo, que, para quienes cuentan con capacidad creadora, no tienen por qué ser incompatibles con los ajustes; d) tratar de recordar lo que nos une, y 
respetar lo que nos separa, porque agitar solo lo que puede separarnos es, hoy, más que nunca, letal.” El papel de la educación cívica, principalmente en los centros educativos y en los medios de comunicación social, es un instrumento para la difusión y consolidación de éstos valores.

c) El capitalismo actual debería transformarse sustancialmente; y compartir los valores humanos de la sociedad en la que se inserta y en la que actúa, si no quiere ser el artífice de su desaparición o de su degradación hasta límites intolerables. El capitalismo es un sistema económico pero también social. Hace falta también y como consecuencia de lo anterior una nueva cultura empresarial.

d) La imposición de ciertas tasas o las transacciones internacionales (la llamada "tasa Tobin"), la competitividad real de los mercados, y la llamada "responsabilidad social corporativa", podrían ser algunos de los medios alternativos de su funcionamiento actual. Se habla de reformas, y a veces de recortes necesarios, con la finalidad pretendida de "salvaguardar" y "asegurar" el Estado de Bienestar, cubriendo su déficit; pero a veces lo que se esconde es su disminución mayor o en su caso la desaparición del mismo. Este debe mantenerse. Estado, mercado y sociedad civil; son complementarios y no antitéticos. La potenciación y la hipervaloración del capitalismo financiero sin límites, provoca sustancialmente una eliminación progresiva de las instituciones democráticas y de los derechos sociales conquistados por los ciudadanos a lo largo de la historia; confundiéndose crecimiento económico y estabilidad presupuestarias.

e) El crecimiento económico no siempre equivale a desarrollo económico, y a la redistribución justa personal y territorial de la renta. El desarrollo hoy, es "holístico", es integral y plural; y supone a la vez, contemplar sus facetas o aspectos complementarios, tales como: el económico, el social, el territorial o cohesión territorial, y el ecológico. La aportación del pensamiento de Keynes, pienso que a pesar del nuevo contexto, es útil y adecuada, ya que como el citado autor señaló en su día, el libre mercado dejado a su voluntad descontrolada, produce no sólo desigualdades, sino también y sobre todo efectos difuminados y el desequilibrio y la falta de sostenibilidad del propio sistema económico. Se olvida a veces también, que el principal teórico del capitalismo surgido con motivo de la Revolución Industrial, Adam Smith, reconociese expresamente el papel limitador del Estado frente a los excesos de los mercados; el cual a su vez también habló de la "ética de la simpatía", la interdependencia y la complejidad de los factores y variables existentes, conducen a una visión y soluciones globales.

f) Parece haber un amplio consenso respecto, a que "el Estado social tal como lo conocemos no logrará sobrevivir mucho" (Sotelo, 2010:396), fruto de diversas causas, como antes he señalado; pero eso no implica necesariamente su muerte, sino su transformación.

g) Ahora bien, el debilitamiento y la crisis múltiple del Estado de Bienestar, no implican en absoluto su desaparición. Como antes he señalado, hay que reinventarlo, y ello será en función de qué modelo de democracia y de sistema político que se diseñe y se desarrolle; y ello en un contexto de mutaciones y problemas estructurales notables en la economía y en la sociedad (movimientos migratorios, interculturalidad, explosión democrática, crisis energética y ecológica, etc.). Una democracia política "fuerte", deliberativa, participativa y transparente; y no "intervenida" ni "oligárquica"; implicara sin duda una democracia social adecuada. Un Estado moderno y modesto, no implica un Estado "asocial".

h) Fruto del cambio de modelo de Estado, y de modelo en concreto del Estado de Bienestar, hace falta el diseño y el desarrollo de forma democrática, de un nuevo modelo de "contrato social" y de relaciones laborales; que diesen respuesta a la actual demanda y 
realidad social. El nuevo modelo de contrato social, se caracterizaría por Mayor Zaragoza (2.000), por las notas siguientes: a) la lucha contra la pobreza; b) la conservación del medio ambiente; c) la potenciación de la educación y la cultura de las personas a lo largo de todo su ciclo vital; y d) valores éticos que impregnen las instituciones. La crisis actual puede ser un buen momento para la reflexión y para un cambio y reorientación positivo y proactivo del sistema político y social.

i) "El municipio de Bienestar", dada la proximidad de éste al ciudadano, y la complementariedad entre lo local y lo global, aparece como una respuesta institucionalorganizativa frente a la crisis del Estado de Bienestar, y para el logro de la "sociedad del Bienestar". El municipio es además, un lugar de encuentro, de sociabilidad, y de identidad personal y comunitaria; en donde "la política no es algo abstracto, son las realidades, la solución de las necesidades concretas de nuestros vecinos; desde ese compromiso con la realidad más inmediata, el municipio se convierte en escuela de ciudadanía. En el municipio nos reconocemos y reconocemos a los otros desde la realidad concreta de la vida de cada día (Rodríguez Maciá, 2011:191). El papel del territorio, es hoy clave lograr la cohesión económica y social. Las políticas públicas sociales pueden en muchos casos, aplicarse y evaluarse mejor en el ámbito local, que en el estatal o subnacional; y además prestarse con carácter complementario a las anteriores.

j) El fortalecimiento frente a la debilidad estatal y de sus instituciones, es un requisito previo e imprescindible para el diseño, ejecución y evaluación de las políticas públicas sociales. No hay democracia y prestaciones sociales, sin estructuras políticas y administrativas sólidas y estables.

k) En la reinvención y/o reorientación actual de las políticas públicas sociales, exigen numerosos y varios retos concretos, y entre ellos destacaría los siguientes: a) el primero y principal, son las limitaciones financieras y presupuestarias, que impiden y frenan la posibilidad de su prestación. El modelo tributario y de desarrollo, las condicionan sin duda. La búsqueda de financiación alternativa a la pública, cara a las prestaciones complementarias de las básicas y universales es una fórmula adecuada, siempre que se desarrolle con control público y con prudencia. La introducción posible de tasas, así como las variadas fórmulas de copago, por las prestaciones sociales; en ese caso, deberán ser sin vulnerar los principios de igualdad y de justicia social; y ello por razones fundadas y no coyunturales e improvisadas, de compensar el déficit público; b) la priorización y la selección de políticas públicas sociales, es un proceso político; que debe ser lo más democrático, pluralista y transparente posible. Los presupuestos participativos son un instrumento válido para ello; c) las políticas públicas en general, y también las sociales, son y deben ser transversales; d) el déficit público y la adaptación y la reorientación del Estado de Bienestar, no debe suponer una vuelta atrás al mero Estado Asistencial caritativo, de beneficencia y paternalista. No puede olvidarse el proceso de la conquista histórica de derechos sociales por los ciudadanos, objeto además de constitucionalización en la mayoría de los países; e) el diseño previo y la ejecución de las políticas públicas sociales deben de partir del conocimiento y del análisis exhaustivo de la realidad social de cada país, a través del examen de los distintos indicadores sociales (básicamente: los movimientos migratorios; las tasas de nacimiento, muerte y envejecimiento, y población activa); f) deberán contemplarse con cuidado y con separación nítida, los procesos de territorializacion y de localización de las mismas. La importancia de los colectivos destinatarios; y la fragmentación social y cultural, son aspectos hoy relevantes; g) el principio clásico de universalización, deberá hoy ser complementado y atemperado con el de personalización. Las lógicas de la igualdad y de la diversidad, deben complementarse e 
integrarse; h) la solidaridad y la justicia social, como principios a lograr y como valores orientadores, o se plasman en la consecución de la cohesión económica y social interpersonal, intergeneracional e interterritorial. La planificación sigue siendo un instrumento muy válido para ello; i) la lucha contra la exclusión social, no es sólo una política pública social, sino que es también un instrumento imprescindible de inclusión y de socialización. No cabe pensar en democracia hoy, con exclusión social, ya que son valores y realidades antitéticas.

1) El llamado "tercer sector" puede ser también una alternativa posible, viable y eficaz, con un carácter complementario del público, cara a la prestación de bienes y servicios públicos, pero especialmente los de carácter social y cultural. No todo lo público es equivalente a estatal. El tercer sector es ante todo y además, la presencia en una sociedad civil y de una pluralidad de instituciones (ONG.'s, fundaciones, cooperativas y movimientos sociales diversos), que tienen rasgos comunes y a la vez diferentes de las estrictamente publicas y las del mercado. No tienen ciertamente las mismas limitaciones legales y presupuestarias que las instituciones públicas, pero en cambio poseen relativa flexibilidad organizativa y procedimental, y no tienen como finalidad esencial el lucro; buscando la eficacia y la calidad en el servicio antes que el mero coste-beneficio. Juegan además a su favor, las características de su capacidad de autoorganizacion, más fácil y mayor creatividad e innovación. Estamos en todo el mundo en un momento de crecimiento espectacular y exponencial de éstas instituciones, que además de fomentar la participación ciudadana y de la sociedad civil, están contribuyendo al mantenimiento de valores sociales y al "aligeramiento" del volumen organizativo público. Su éxito dependerá a su vez, de diversos factores y entre ellos, destacaría: a) de su liderazgo; b) de su capacidad organizativa y de gestión adecuada de sus recursos; c) de su conexión y coherencia con la realidad social; y d) de la búsqueda de financiación alternativa, no clientelar.

m) La educación en el más amplio sentido, y en particular su ética, desde la escuela a la universidad, aparece como un instrumento necesario y válido. Así lo ha puesto de manifiesto, entre otros, Klisberg (2006:21) "Es fundamental al respecto el papel que puede jugar la educación en todos sus ámbitos y particularmente en las universidades. Las nuevas generaciones de profesionales deber de ser preparados a fondo en sus responsabilidades éticas".

n) Hay que desarrollar y consolidar "el capital social", en feliz expresión de Robert Putnam, siendo hoy un concepto plenamente aceptado, e incluso considerado fundamental por el Banco Mundial. La creación y desarrollo de redes de cooperación y alianzas publicoprivadas, aparecen como claves y necesarias en ésta época que vivimos.

ñ) Hay que potenciar el papel del voluntariado, que juega un papel complementario muy importante en ocasiones, y es una expresión de la sociedad civil y del "capital social". Sus asociaciones deberían financiarse y apoyarse en base a criterios objetivos serviciales, y no clientelares. Especial atención requieren las asociaciones de personas jóvenes y de la tercera edad, con retos y características diferentes.

o) El liderazgo político, de carácter básicamente: democrático, trasformador, relacional, empático, integrador y participativo; aparece como un actor fundamental de los procesos de cambio social, y máxime en situaciones de crisis.

Las últimas encuestas del CIS ponen de relieve en España, el desprestigio de la clase política y del sistema de partidos y electoral; unido este hecho al fenómeno bastante generalizado de corrupción política y administrativa, fruto de "la burbuja inmobiliaria y crediticia", causas principales de la crisis que se sufre. 
p) La rendición de cuentas y la responsabilidad (la accountability) son unos instrumentos fundamentales para no sólo la lucha contra la corrupción, sino para la transparencia y la democracia fuerte y de calidad.

q) La eficacia y la calidad de las prestaciones de bienes y servicios públicos, fruto de las políticas públicas sociales; requieren mínimamente unas Administración Publicas modernas y una función pública (o servicio civil de carrera en expresión iberoamericana) profesional y con valores públicos, especialmente la ética pública.

r) La gestión de las políticas públicas trasversales sociales, debe ser lo más transversal posible. La transversalidad debería abarcar esencialmente estas tres dimensiones o aspectos: a) el espacial; b) el causal; y c) el temporal.

s) La crisis compleja y de múltiples facetas actual, a pesar de su importancia, requiere soluciones y respuestas estratégicas, dotadas de la suficiente flexibilidad y capacidad de adaptación; en el contexto de sociedades abiertas y dinámicas.

La crisis actual del Estado de Bienestar, y su necesidad inevitable de cierta reorientación y actualización, como defensa y salida de la presente situación; no puede implicar su alteración sustancial o incluso su pretendida desaparición, en base a una coyuntura actual, y a la precipitación y a la improvisación interesados del neoliberalismo radical. En ese sentido, entre otros, ya hace años, Amartya K. Sen, entre otros, decía así: “....En efecto, el Estado de Bienestar, tal como lo conocemos, es uno de los grandes logros de la civilización europea, es una de las grandes contribuciones de Europa al mundo. El resto del mundo ha emprendido esta dirección, imitándolo cada vez más, valorando positivamente, en muchos aspectos, lo que ha sucedido en Europa desde que concluyera la segunda guerra mundial.

No se sacrifican los grandes logros de la civilización porque en un determinado momento se están atravesando problemas a corto plazo.

La idea subyacente del Estado de Bienestar, en cierto sentido, es la de una sociedad interdependiente, donde la idea de la responsabilidad está ampliamente compartida..."

Para finalizar, quisiera hacer mías también las palabras de Delcourt, que ponen de relieve sintéticamente la situación del pasado, pero también la presente y futura, al decir: “... ¿Regresa el Estado tras un largo eclipse? La intervención pública, antes vilipendiada, ahora es abiertamente bienvenida, celebrada, adecuada con todas las virtudes por aquellos mismos que hace poco aclamaban su retirada en un nombre de la globalización "feliz" y de la absoluta alianza en las capacidades del "mercado autoregulado" para lograr el crecimiento y producir bienestar.

El poder público, ante un edificio financiero inmóvil, está llamado a subsanar las pruebas de una economía internacional a la deriva, asestando un golpe directo al conocido dogmatismo del "todo-mercado" y desacreditado las tesis neoliberales más ortodoxas que hasta el momento dominaban la reflexión económica y orientaban la acción política. Regresan las políticas keynesianas que durante más de veinte años fueron vistas con desconfianza y reaparece el proteccionismo, como símbolo de estos tiempos aun corriendo el riesgo de agravar la crisis.

Como prueba de ello está el debate internacional, emprendido nuevamente desde mediados de los años 90, sobre la importancia de las políticas sociales, su papel y su impacto en el desarrollo.

El Banco Mundial, sometido a un juego avivado por las críticas ante los desastres sociales engendrados por las políticas de ajuste, se inserta así desde hace una decena de años en la formulación de un nuevo paradigma de desarrollo, que tiende a reintegrar los principios del desarrollo social y de la intervención pública...” (2010:7 y 8). 
La salida a esta crisis estructural que estamos viviendo es pues sobre todo y ante todo de carácter múltiple; es decir social, política y ética; y no sólo económica. Urge pues, ante la situación actual, la búsqueda de una nueva regulación de los mercados, instituciones y de los valores imperantes junto a medidas y políticas estratégicas y eficaces.

\section{BIBLIOGRAFÍA}

ADOLPH, C. (2012), The myth of Neutrality: Bankers, Bureaucrats and Central Bank Politics. New Cork, Cambridge University Press.

AGUILAR VILLANUEVA, L. F. (2006), Gobernanza y Gestión Pública. México, FCE.

B.I.D., PNUD., CEPAL. (1995), Informe de la Comisión Latinoamericana y del Caribe sobre el Desarrollo Social, Washington.

BANCO INTERAMERICANO DE DESARROLLO (1997), Libro de consulta sobre participación. Washington.

BANCO INTERAMERICANO DE DESARROLLO (1998), Informe de progreso económico y social. Washington.

BARBER, B. (2004), Democracia fuerte. Política Participativa para una nueva época. Huelva, Almenara Estudio.

BECK, U. (2005), ¿Qué es la globalización? Falacias del globalismo, respuesta a la globalización. Barcelona, Paidós.

BECK, U. (2000), Un nuevo mundo feliz. La precariedad del trabajo en la era de la globalización. Barcelona, Paidós.

BILBENY, N. (1999), Democracia para la diversidad. Barcelona, Ariel.

BRESSER PEREIRA, L. C. y CUNILL GRAU, N. (eds.) (1998), Lo público no estatal en la reforma del Estado. Buenos Aires, Paidós.

CANALES ALIENDE, J. M. (2003), "La crisis del Estado de Bienestar y su incidencia en las Administraciones Públicas", en: J.F. Tezanos, y A. Alaminos, Tendencias en desvertebración social y en políticas de solidaridad. Madrid, Sistema.

CANALES ALIENDE, J. M. (2012), Lecciones de Administración y de Gestión Pública. Alicante, Servicio de Publicaciones de la Universidad de Alicante.

CARRILlO FLORES, F. y CORDERO, L. A. (2007), Hacia el Buen Gobierno. Tareas aún pendientes. San José de Costa Rica, Fundación Arias para la Paz y el Progreso Humano.

CASTELLS, M. (1997), La era de la información. Economía, sociedad, cultura. Madrid, Alianza.

CORTINA, A. (2012), "Ética en tiempos de crisis", en: El País, 4 enero, pp. 29 y 30.

CROUCH, C. (2004), Postdemocracia. Madrid, Taurus.

CROZIER, M. (1996), La crisis de la inteligencia. Ensayo sobre la incapacidad de las élites para reformarse. Madrid, Traducción y publicación del Ministerio de la Presidencia y del BOE

CROZIER, M. (1998), Estado Moderno, Estado Modesto. México, FCE.

DAVIDSON, P. (2009), The Keynes Solution: the Path to Global Economic Prosperity. Nueva York, Palgrave Macmillan.

DELCOURT, L. (coord.) (2010), El regreso de la intervención del Estado. Hacia dónde van las políticas sociales. Editorial Popular, S.A., Madrid.

DELONG, B. y SUMMERS, L. (2012), Fiscal Policy in a Depressed Economy. Washington, Brookings Institution.

DONAHOE, J. (1991), La decisión de privatizar. Fines públicos y medios privados. Barcelona, Paidós. DRUCKER, P. F. (1993), La sociedad postcapitalista. Barcelona, Apóstrofe.

ESPING-ANDERSEN, G. y PALIER, B. (2010), Los tres grandes retos del Estado del Bienestar. Barcelona, Ariel.

ESTEFANÍA, J. (1996), La nueva economía. La globalización. Madrid, Temas de debate, El País. 
FERnÁNDEZ ALBERTOS, J. (2012), Democracia intervenida. Políticas económicas en la gran recesión. Madrid, Los libros de la Catarata.

FERRARO, A. E. (2009), Reinventando el Estado. Por una Administración Pública democrática y profesional en Iberoamérica. Madrid, I.N.A.P.

FUKUYAMA, F. (2012), "The Future of History. Can Liberal Democracy Survive. The Decline of the Middle Class?" en: Foreing Affairs, January-February, pp. 53 a 61.

GARCÍA PELAYO, M. (1977), Las transformaciones del Estado contemporáneo. Madrid, Alianza. GOMA, J. (2009), Ejemplaridad Pública. Madrid, Taurus.

HABERMAS, J. (1997), Más allá del Estado nacional. Madrid, Trotta.

HELD, D. (2012), Cosmopolitismo, Ideas y Realidades. Madrid, Alianza.

INNERARITY, D. (2009), El futuro y sus enemigos. Una defensa de la esperanza política. Barcelona, Paidós.

JAUREGUI, G. (2000), La democracia planetaria. Oviedo, Ediciones Nobel.

KLISBERG, B. (2006), Más ética. Más desarrollo. Madrid, M.A.P. e I.N.A.P.

KLISBERG, B. (comp.) (2005), La agenda ética pendiente de América Latina. México, FCE.

KRUGMAN, P. (2012), Acabad con esta crisis. Barcelona, Crítica.

LUHMANN, N (2002), Teoría política del Estado de Bienestar. Madrid, Alianza.

MAYOR ZARAGOZA, F., et al. (2000), Un mundo nuevo. Barcelona, Centro UNESCO de Cataluña.

MEDELLÍN TORRES, P. (1998), El retorno a la política. La gubernamentalización del gobierno. Bogotá, Ediciones Tercer Mundo, S.A.

MEDELLÍN TORRES, P. (2004), La política de las políticas públicas. Propuesta teórica y metodología para el estudio de las políticas públicas en países de frágil institucionalidad. Santiago de Chile, Naciones Unidas, CEPAL.

MENY, I. y THOENING, J.C. (1992), Las políticas públicas. Barcelona, Ariel.

OLLER y SALA, M. D. (2002), "Un futuro para la democracia. Una democracia para la gobernabilidad mundial", en: Cuadernos de Cristianisme i Justicia, Barcelona, $\mathrm{n}^{\circ} 115$.

P.N.U.D. (2004), La democracia en América Latina. Hacia una democracia de ciudadanas y ciudadanos. Nueva Cork, Naciones Unidas.

PUTNAM, R. (1994), Making Democracy Work. Princenton University Press.

RODRÍGUEZ MACIÁ, M. (2008) "Herramientas de gestión local en contextos pluriculturales", en: Territorialización de las Políticas Públicas. San José, Costa Rica, Fundación DEMUCA, pp. 189-190. RODRIK, D. (2011), The globalization Paradox. Democracy and the Future of the World Economy. New York, M.N. Norton.

ROITMAN, M. (2005), Las razones de la democracia en América Latina. México, Siglo XXI.

ROSANVALLON, P. (2010), La legitimidad democrática, imparcialidad, reflexividad y proximidad. Barcelona, Paidós.

ROSE-ACKERMAN, S. (2001), La corrupción y los gobiernos. Causas, consecuencias y reforma. Madrid, Siglo XXI.

ROTHKOPF, D. (2008), El club de los elegidos. Como la élite global gobierna el mundo. Barcelona, Ediciones Urano.

SÁNCHEZ CUENCA, I. (2010), Más democracia y menos liberalismo. Madrid, Katz.

SEBASTIÁN, L. de (1996), La solidaridad. Barcelona, Ariel.

SEMPERE NAVARRO, A. V. y otros (2001). Politicas Sociolaborales. Pamplona, Eunate.

SEN, A. K. (1999), "El futuro del Estado de Bienestar" en: Estape, F. (2009), Los economistas y su trastienda. Barcelona, Planeta, pp. 354 a 377.

SEN, A. K. y KLISBERG, B. (2007), Primero la gente. Bilbao, Ediciones Deusto.

SMITH, P. H. (2008), La democracia en América Latina. Madrid, Universidad de Alcalá de Henares. SOROS, G. (2002), Globalización. Barcelona, Planeta.

SOTELO, I. (2010), El Estado Social. Antecedentes, origen, desarrollo y declive. Madrid, Trotta.

STIGLITZ, J. (2002), El malestar en la globalización. Madrid, Taurus.

SUBIRATS, J. (2011), Otra sociedad ¿Otra Política? De "no nos representan” a la democracia común. Barcelona, Icaria. 
TERMES I ANGLES, F. (2005), El Código de ética. Normas básicas para su diseño en la Administración Pública. Barcelona. Gestión 2000.

TEZANOS, J. F. (ed.) (1996), La democracia postliberal. Madrid. Sistema.

TOURAINE, A. (1993), Crítica de la modernidad. Madrid, Temas de Hoy.

TRINIDAD REQUENA, A. y PÉREZ SÁNCHEZ, M. (2010), Análisis y evaluación de políticas sociales. Madrid, Tecnos.

UÑA JUÁREZ, O. (dir.) (2010), La importancia geoestratégica del África Subsahariana, Madrid, Ministerio de Defensa.

UÑA JUÁREZ, O. y GUTIÉRREZ RESA, A. (2010), Integración de los inmigrantes a través de los servicios sociales en la Comunidad de Madrid, Madrid, UNED.

VALLES, J.M. y BALLART, X. (ed.) (2011), Política para apolíticos. Barcelona, Editorial S.A.

VARELA BARRIOS, E. (2007), La soberanía transformada. Bogotá, Ecoe Ediciones y Universidad del Valle.

VIDAL BELTRÁN, J. M. y PRATS CATALA, J. (coord.) (2005), Gobernanza. Diálogo euroiberoamericano. Madrid, M.A.P. e I.N.A.P.

VILLORIA MENDIETA, M. (2006), La corrupción política. Madrid, Síntesis.

VILLORIA MENDIETA, M. (2007), El servicio civil de carrera en Latinoamérica. Diagnóstico, causas y propuestas. Madrid, I.N.A.P.

WORLD BANK (1998), Beyond the Washington consensus. Institutions leather. Washington.

WORLD BANK (2000), The Quality of Grouth, Washington.

RECIBIDO: $23 / 3 / 2013$

ACEPTADO: $27 / 4 / 2013$

\section{Breve currículo:}

\section{José Manuel Canales Aliende}

Catedrático de Ciencia Política y de la Administración de la Universidad de Alicante. Doctor en Derecho Público por la Universidad Complutense de Madrid; Diplomado en Sociología Política del Instituto de Estudios Políticos de Madrid; Licenciado en Derecho por la Universidad de Deusto. Graduado en Ciencias Empresariales por ICADE (Madrid); Funcionario por oposición de varios Cuerpos Superiores de la Administración del Estado. Consultor de la OCDE, Banco Mundial y de la Unión Europea. Evaluador de varias Agencias: ANECA, AGAUR, ACSUG y ACSUCYL. Miembro del consejo académico de varias revistas indexadas de Ciencias Sociales de España y del extranjero. Autor de unas cien publicaciones (libros, capítulos de libros y artículos de revistas) sobre la Modernización del Estado, el Gobierno, la Administración y la Gestión Pública. Profesor de la Universidad Complutense desde 1975 hasta el 2001. 